\title{
Variability of self reported measures of alcohol consumption: implications for the association between drinking in pregnancy and birth weight
}

\author{
Altamiro da Costa Pereira, Jørn Olsen, Simon Ogston
}

\begin{abstract}
Study objective-To describe the intrasubject variability of self reported maternal alcohol consumption using different ways of collecting information and to analyse the implications of this variability for research into the effect of low to moderate maternal alcohol consumption on birth weight.

Design-This was a longitudinal study. Self reported maternal alcohol consumption before, during, and after pregnancy was assessed on four occasions over two years. The data were collected by two self administered questionnaires and during two personal interviews (one by phone and another face to face).
\end{abstract}

Settings-The Obstetrics Department, Odense University Hospital, Odense, Fünen, Denmark.

Participants-A total of 2880 pregnant women were recruited consecutively from the hospital catchment area. Altogether 328 pregnant women and their babies were selected. All women who reported an average alcohol consumption of five drinks or more per week were recruited to the study (164 women) and a 1:1 control group was selected from the remaining women based upon two matching criteria: expected date of delivery and the women's year of birth. Some 279 women $(85 \%)$ completed the study.

Measurements and main results-self reported alcohol consumption (number of drinks per week) and birth weight (g) were the main outcomes. Women's self reported alcohol consumption varied over time and according to the data collection method. When different methods of data collection were used to assess alcohol intake in similar periods of time, significant differences in reporting were found despite the relatively high correlations between the measurements. Although a consistent reduction in birth weight with increasing consumption of alcohol was found, there were differences in the shape and strength of this association when comparing the six available alcohol measurements.

Conclusions-The type of questions used, the way the data were collected, the period of time referred to, and the time the questions were asked, should be taken into consideration when describing the drinking pattern of pregnant women. Furthermore, birth weight results from studies that have used different alcohol measures should be interpreted or compared with caution because of possible large differences resulting from the differing methods of assessing fetal exposure to alcohol.

f Epidemiol Community Health 1993; 47: 326-330

Few researchers doubt that heavy drinking in pregnancy may harm the fetus and cause a reduction in fetal growth and mental development. The fetal alcohol syndrome is a recognized disease ${ }^{1}$ but there is no consensus on the impact of low to moderate alcohol consumption during pregnancy. In most countries only a few women drink heavily during pregnancy but a low to moderate intake (such as less than two drinks per day on average) is common. In many countries such an intake is considered socially and medically acceptable. If a low to moderate alcohol consumption during pregnancy interferes with fetal growth it could have major public health implications. Existing research does not support evidence of a strong association between a low to moderate alcohol intake during pregnancy and severe birth defects, but an association with mild developmental disorders and fetal growth is possible. ${ }^{2 \cdot 5}$

The psychological and neurological statuses of newborns are difficult to measure and suffer from large measurement errors. This fact, the easy access to birth weight, and the recognition that low birth weight is associated with a range of adverse conditions, ${ }^{6}$ probably explain why birth weight has been the outcome variable most often considered in relation to maternal alcohol use. On the other hand, we lack a reliable biological measure of moderate alcohol intake and are left with self reported data on alcohol consumption, collected by questionnaire or by interview.

The first aim of this study is to describe changes in alcohol consumption during pregnancy and the variability of self reported maternal alcohol consumption when using different methods of collecting the information for the same time period. The second aim is to analyse how such variability may affect the interpretation of data linking low to moderate maternal alcohol consumption to birth weight.

\section{Methods}

The study is part of the European concerted action entitled EUROMAC, a longitudinal study of alcohol intake during pregnancy and child development. ${ }^{7}$ From 1 January 1988 to March 1989 all pregnant women in a well defined area (Odense municipality, Funen, Denmark) received a short self administered questionnaire at their first visit to a midwife centre (usually in the 12 th week of gestation). In total 2880 women 
$(88.9 \%)$ completed the questionnaire, which was then sent to the department of Social Medicine, Odense University. All women who reported an average consumption of five drinks or more per week were recruited to the study (164 women), as well as a 1:1 control group selected from the remaining women and based upon two matching criteria: expected date of delivery and the women's year of birth. Three hundred and thirteen women were then interviewed by phone in the 28 th week of gestation by one interviewer who was blind to the data in the self reported questionnaire. In the 36 th week of gestation the women received a more comprehensive self administered questionnaire about nutrition, environmental exposures, and alcohol intake during pregnancy (304 responded). Eighteen months after the delivery all mothers were invited to bring their children to the hospital and were asked to complete a test (a Bayley developmental test); at that time they had a face to face interview (with the same interviewer) which included questions on their average consumption of alcohol during pregnancy. The interview was again done without any knowledge of the previous responses and 279 mothers and their children participated. After excluding all the women with missing data in any of the alcohol questions, the answers of 272 respondents ( $83 \%$ of the initial 328 women selected for this study) were compared.

The alcohol questions in this survey are shown in table I in relation to time of data collection and the method used. All these questions related to maternal alcohol consumption over a one week period. A letter has been allocated to each question, and questions are referred to by this letter throughout this paper. Questions were classified according to their type: daily if the questions asked about alcohol intake day by day on specific days (for example "last Saturday"), average daily if they asked about usual or average consumption on each day of the week (for example, "on an average Saturday"), and average weekly if they asked about total consumption for an average week. Regardless of the type of question asked, all alcohol measurements used in this study were later coded in drinks per week: a drink being a bottle of beer, a glass of wine, or a glass of spirits. The average alcohol content of a "drink" in Denmark is about $12 \mathrm{~g}$. In the analyses, all the numbers of drinks were rounded down to the nearest integer. In addition, as all the other questions required integer responses, responses of $<1$ drink per week in the two questions asked at the 36 th week of gestation were also recorded as zero.

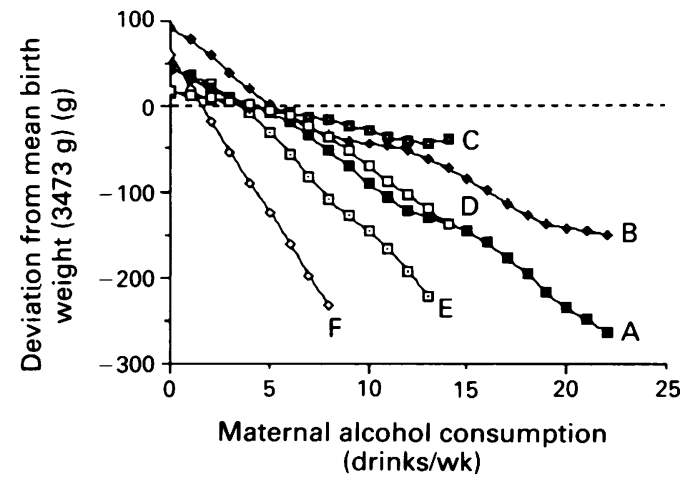

Smoothed plot of birthweight against various alcohol measures. Questions $A$ to $F$ are fully defined in Table I. Questions $C, D$, and $E$ are related to maternal alcohol consumption in these weeks of gestation. (C) refers to weeks 4-12 of gestation; (B) pre-pregnancy; (D) week 27; $(A)$ pre-pregnancy; $(E)$ weeks $0-36$; and $(F)$ overall pregnancy.

To smooth the plot of birth weight against alcohol (figure), we used the generalised additive model procedure described by Hastie and Tibshirani. ${ }^{8}$ For each value $\mathrm{x}_{0}$ of alcohol, a local weighted regression of birth weight on alcohol is done, with the weights chosen to give large influence to values near $x_{0}$. The predicted value of $y$ at $x_{0}$ is then calculated and the procedure repeated for $x_{0}$ over the entire range of alcohol, yielding a smoothed plot. Hastie and Tibshirani ${ }^{8}$ show how the procedure can be generalised to allow for covariates, so that the outcome variable may be expressed as the sum of a series of functions of each covariate. We used a weight function $\mathrm{w}(\mathrm{x})=\left[1+\left(\mathrm{x}-\mathrm{x}_{0}\right)^{2} / \mathrm{s}^{2}\right]^{-1}$ with $\mathrm{s}$ set to 5 which was observed to give a smooth plot. Each line in the plot is drawn only up to the 99 th centile of the corresponding alcohol distribution to exclude parts of the curve based on very few data points.

\section{Results}

VARIABILITY OF SELF REPORTED MATERNAL ALCOHOL CONSUMPTION

There were significant differences in the reported alcohol consumption between the answers to the two questions asked at the 36th week of gestation, one of which referred to the pre-pregnancy period (question B), and the other (question E) to the first 36 weeks in pregancy (table II). More unexpec-
Table I The phrasing, methods, and timing of questioning

\begin{tabular}{|c|c|c|c|}
\hline $\begin{array}{l}\text { Method and time } \\
\text { of data collection }\end{array}$ & Question & Type of question & Type of answer \\
\hline $\begin{array}{l}\text { Question at } 12 \text { th week of ges- } \\
\text { tation }\end{array}$ & $\mathrm{C}$ & $\begin{array}{l}\text { Average weekly: } \\
\text { "Over the last } 2 \text { months, on average, how many } \\
\text { drinks did you have per week?" }\end{array}$ & $\begin{array}{l}\text { Number of drinks of beer, } \\
\text { wine and spirits }\end{array}$ \\
\hline \multirow[t]{2}{*}{$\begin{array}{l}\text { Interview at the } 28 \text { th } \\
\text { week of gestation }\end{array}$} & D & $\begin{array}{l}\text { Daily: } \\
\text { "Please tell me exactly how much you drank } \\
\text { each day over the last } 7 \text { days" }\end{array}$ & $\begin{array}{l}\text { Number of drinks of beer, } \\
\text { wine and spirits }\end{array}$ \\
\hline & A & $\begin{array}{l}\text { Average daily: } \\
\text { "Before you became pregnant how much did you } \\
\text { usually drink each day of the week?" }\end{array}$ & Same as above \\
\hline \multirow[t]{2}{*}{$\begin{array}{l}\text { Questionnaire at the } 36 \text { th } \\
\text { week of gestation }\end{array}$} & $\mathrm{E}$ & $\begin{array}{l}\text { Average weekly: } \\
\text { "How many bottles of beer have you on average been } \\
\text { drinking per week during pregnancy?" (similar for } \\
\text { glasses of zuine and glasses of spirits) }\end{array}$ & $\begin{array}{l}\text { Categorical: } 0,<1,1-4 \text {, } \\
5-9,10-14,15-19,20+\end{array}$ \\
\hline & B & $\begin{array}{l}\text { Same as above, only addressing the pre- } \\
\text { pregnancy period }\end{array}$ & Same as above \\
\hline $\begin{array}{l}\text { Interview at the } 18 \text { th month } \\
\text { after pregnancy }\end{array}$ & $\mathrm{F}$ & $\begin{array}{l}\text { Average daily: } \\
\text { "Since pregnancy how much have you usually drunk } \\
\text { on each day of the week?" }\end{array}$ & $\begin{array}{l}\text { Number of drinks of beer, } \\
\text { wine and spirits }\end{array}$ \\
\hline
\end{tabular}


Table II Self reported maternal alcohol consumption: percentage of women in each of the categories of alcohol consumption and summary statistics (in number of drinks per week) according to the questions asked $(n=272)$

\begin{tabular}{|c|c|c|c|c|c|c|}
\hline $\begin{array}{l}\text { Time of data collection: } \\
\text { Period referred to: } \\
\text { Question: }\end{array}$ & $\begin{array}{l}\text { 28th week } \\
\text { Pre-pregnancy } \\
A\end{array}$ & $y_{B}^{36 \text { th week* }}$ & $\begin{array}{l}\text { 12th week } \\
\text { 4-12th week } \\
C\end{array}$ & $\begin{array}{l}28 \text { th week } \\
27 \text { th week } \\
D\end{array}$ & $\begin{array}{l}\text { 36th week } \\
0-36 \text { th week } \\
E\end{array}$ & $\begin{array}{l}18 \text { months after delivery } \\
\text { Overall pregnancy } \\
F\end{array}$ \\
\hline $\begin{array}{l}0 \text { drinks/wk (\%) } \\
1 \text {-4 drinks/wk (\%) } \\
5+\text { drinks/wk (\%) } \\
\text { Mean } \\
\text { Median } \\
\text { (99\% range) }\end{array}$ & $\begin{array}{l}29 \\
39 \\
32 \\
3 \cdot 9 \\
3 \cdot 0 \\
(0-23 \cdot 0)\end{array}$ & $\begin{array}{l}6 \\
46 \\
48 \\
5 \cdot 9 \\
3 \cdot 0 \\
(0-22 \cdot 5)\end{array}$ & $\begin{array}{l}18 \\
34 \\
48 \\
4 \cdot 3 \\
4 \cdot 0 \\
(0-15 \cdot 0)\end{array}$ & $\begin{array}{l}21 \\
53 \\
26 \\
3 \cdot 2 \\
2 \cdot 0 \\
(0-15 \cdot 0)\end{array}$ & $\begin{array}{l}19 \\
57 \\
24 \\
2 \cdot 9 \\
1 \cdot 0 \\
(0-13 \cdot 5)\end{array}$ & $\begin{array}{l}49 \\
41 \\
10 \\
1 \cdot 6 \\
1 \cdot 0 \\
(0-9 \cdot 0)\end{array}$ \\
\hline
\end{tabular}

*Week of gestation. Questions $\mathrm{A}$ to $\mathrm{F}$ are fully defined in table I tedly, there were significant differences in the reported alcohol consumption when comparing two responses made eight weeks apart and both referring to the pre-pregnancy period (questions $\mathrm{A}$ and B). Similarly, a significantly lower maternal alcohol use during the overall pregnancy period was reported with the question asked 18 months after the delivery (question $\mathrm{F}$ ), when compared with the question referring to the first 36 weeks in pregnancy (question $E$ ). The pattern of changes in the reported pre-pregnancy alcohol use is presented in table III-A where, eight weeks later, $40 \%$ of women reported a higher alcohol consumption compared with only $4 \%$ who reported a lower intake. In line with these general shifts in the alcohol distributions, Kendall's correlation coefficients (Kendall's $\tau$ ) between the two prepregnancy reports (questions $\mathrm{A}$ and $\mathrm{B}$ ) was 0.75 and between the two overall pregnancy reports (questions $\mathrm{E}$ and F) was 0.66 (table IV).

By contrast, rather similar overall alcohol consumptions were found between reports referring to the 27th week of gestation and reports covering the first 36 weeks of gestation (questions $D$ and $E$, table II). However, when considering the individual answers, $37 \%$ of women were differently classified when using one or the other report, with nearly equal numbers of women moving into higher or into lower categories of alcohol intake (table III-B). As a consequence Kendall's $\tau$ was only $0 \cdot 56$. Similar two way movements with lower correlation coefficients were found between the question asked at the 12th week of gestation (question $\mathrm{C}$ ) and all of the other questions.
Table III Self reported alcohol consumption according to different questions

\begin{tabular}{|c|c|c|c|c|}
\hline \multicolumn{5}{|c|}{ A Pre-pregnancy alcohol consumption (no of drinks per week) reported at: } \\
\hline \multirow[b]{2}{*}{ 28th week* (question $A$ ) } & \multicolumn{3}{|c|}{ 36th week* (question B) } & \multirow[b]{2}{*}{ Total } \\
\hline & 0 & $1-4$ & $5+$ & \\
\hline $\begin{array}{l}0 \\
1-4 \\
5+ \\
\text { Total }\end{array}$ & 16 & $\begin{array}{r}54 \\
60 \\
10 \\
124\end{array}$ & $\begin{array}{r}8 \\
47 \\
77 \\
132\end{array}$ & $\begin{array}{r}78 \\
107 \\
87 \\
272\end{array}$ \\
\hline \multicolumn{5}{|c|}{ B Alcohol consumption during pregnancy (no of drinks per week) referred to: } \\
\hline \multirow[b]{2}{*}{ 27th week ${ }^{\star}$ (question D) } & \multicolumn{3}{|c|}{$0-36$ th week* (question E) } & \\
\hline & $\overline{0}$ & $1-4$ & $5+$ & Total \\
\hline $\begin{array}{l}0 \\
1-4 \\
5+ \\
\text { Total }\end{array}$ & $\begin{array}{r}30 \\
19 \\
2 \\
51\end{array}$ & $\begin{array}{r}25 \\
103 \\
28 \\
156\end{array}$ & $\begin{array}{r}3 \\
23 \\
39 \\
65\end{array}$ & $\begin{array}{r}58 \\
145 \\
69 \\
272\end{array}$ \\
\hline
\end{tabular}

*Week of gestation. Questions A, B, D, and E are fully defined in table I
SELF REPORTED MATERNAL ALCOHOL

CONSUMPTION AND BIRTH WEIGHT

The figure shows a smoothed plot of birth weight against alcohol. Ten subjects have been excluded because of missing birth weight data. After adjusting for gestational age, mother's smoking habits, and mother's age, a reduction in birth weight can be observed with any of the six different alcohol reports. However, the two questions covering the overall period of pregnancy (questions $\mathrm{E}$ and $\mathrm{F}$ ) showed stronger associations with birth weight as expressed by the lowest values of the mean squared residual. In each of these two measures of alcohol, the reduction in birth weight was around $250 \mathrm{~g}$ for cases with the highest consumption as compared with no consumption and the regression coefficients were statistically significant (table $\mathrm{V}$ ). The two questions asked at the 12th and 28th week of gestation, referring respectively to the alcohol consumptions early in pregnancy and in the 27th week of pregnancy, showed relatively weak associations with birth weight. In particular, the reduction in birth weight with the former question was less than $50 \mathrm{~g}$ over the range of alcohol reported and had nonsignificant regression coefficients (table V). Similar results were found when analyses were restricted to women reporting fewer than two drinks per day (data not shown).

\section{Discussion}

VARIABILITY OF SELF REPORTED MATERNAL ALCOHOL CONSUMPTION

When alcohol intake during different time periods was determined in similar ways, variability in maternal self reports of alcohol intake may reflect a genuine variation in the women's drinking patterns. This may well be the case when comparing the two reports (one referring to the pre-pregnancy period and the other to the first 36 weeks of pregnancy) obtained at the 36th week of gestation by a self administered questionnaire which asked similar types of questions.

When alcohol intake during similar time periods was assessed in different ways, any differences in reporting may be explained by the women's ignorance of their true alcohol consumption, by deliberate misreporting of their intake levels, or by differences in questioning. The latter may explain some of the variability noted between questions $\mathrm{A}$
Table IV Correlation coefficients between the various self reported alcohol measures: Pearson's (lower left triangle) and Kendall's (upper right triangle).

\begin{tabular}{|c|c|c|c|c|c|c|}
\hline $\begin{array}{l}\text { Time of data collection: } \\
\text { Period referred to: } \\
\text { Question: }\end{array}$ & $\begin{array}{l}\text { 28th week } \\
\text { Pre-pregnancy } \\
A\end{array}$ & $\begin{array}{l}36 \text { th week }^{*} \\
B\end{array}$ & $\begin{array}{l}\text { 12th week } \\
4-12 \text { th week } \\
\text { C }\end{array}$ & $\begin{array}{l}28 \text { th week } \\
27 \text { th week } \\
D\end{array}$ & $\begin{array}{l}\text { 36th week* } \\
0-36 \text { th }^{*} \text { week }^{*} \\
E\end{array}$ & $\begin{array}{l}18 \text { months after delivery } \\
\text { Overall pregnancy } \\
F\end{array}$ \\
\hline $\begin{array}{l}\text { A } \\
\text { B } \\
\text { C } \\
\text { D } \\
\text { E } \\
\text { F }\end{array}$ & $\begin{array}{r}1 \cdot 00 \\
.70 \\
.36 \\
.54 \\
.61 \\
.59\end{array}$ & $\begin{array}{l}.75 \\
1.00 \\
.35 \\
.52 \\
.71 \\
.54 \\
\text { Pearson's }\end{array}$ & $\begin{array}{r}.47 \\
.45 \\
1.00 \\
.43 \\
.49 \\
.43 \\
\text { relation coefficien }\end{array}$ & $\begin{array}{l}\text { Kendall's } \\
.56 \\
.56 \\
.51 \\
1.00 \\
.58 \\
.54\end{array}$ & $\begin{array}{l}\text { relation coefficien } \\
.66 \\
.73 \\
.58 \\
.60 \\
1.00 \\
.67\end{array}$ & $\begin{array}{r} \\
.64 \\
.56 \\
.49 \\
.52 \\
.66 \\
1.00\end{array}$ \\
\hline
\end{tabular}

${ }^{\star}$ Week of gestation. Questions $A$ to $F$ are fully defned in table I 
Table V Regression coefficients on birth weight (in g) according to alcohol consumption (in number of drinks per week) adjusted for gestational age, mother's age and smoking habits $(n=262)$. The standard errors are shown in parentheses.

\begin{tabular}{|c|c|c|c|c|c|c|}
\hline $\begin{array}{l}\text { Time of data collection: } \\
\text { Period referred to: } \\
\text { Question: }\end{array}$ & $\begin{array}{l}\text { 28th week } \\
\text { Pre-pregnancy } \\
A\end{array}$ & $\begin{array}{l}36 \text { th week* } \\
B\end{array}$ & $\begin{array}{l}\text { 12th week } \\
\text { 4-12th week } \\
C\end{array}$ & $\begin{array}{l}\text { 28th week* } \\
27 \text { th week* } \\
D\end{array}$ & $\begin{array}{l}\text { 36th week } \\
0-36 \text { th week } \\
\text { E }\end{array}$ & $\begin{array}{l}18 \text { months after delivery } \\
\text { Overall pregnancy } \\
F\end{array}$ \\
\hline $\begin{array}{l}\text { Regression coefficients } \\
\text { (SEM) }\end{array}$ & $-11(8)$ & $-10(5)$ & $-3(8)$ & $-12(6)$ & $-21(9)$ & $-36(12)$ \\
\hline
\end{tabular}

*Week of gestation. Questions $\mathrm{A}$ to $\mathrm{F}$ are fully defined in table I

and $B$ (both referring to the pre-pregnancy period) or between questions $\mathrm{E}$ and $\mathrm{F}$ (both referring to an overall consumption during pregnancy), in table II. In fact, questions of the average daily type (questions $\mathrm{A}$ and $\mathrm{F}$ ) were more often associated with reports of no alcohol use than any other type of question (table II). Since only whole numbers of drinks were recorded, it is likely that women with a genuinely low alcohol consumption (one or two drinks per week) when asked about their average daily intake, would report zero drinks for any average day of the week: these women would therefore be classified as non-drinkers. By contrast, if these women were asked about their total consumption in an average week (or, if they were asked about their actual alcohol intake day by day in a particular week) they would probably report having an intake of one or two drinks and would no longer be classified as non-drinkers. This reasoning could also explain why for reports obtained at the 28th week of gestation and referring to the pre-pregnancy period (question A), there was an unexpectedly greater proportion of women reporting zero drinks per week as compared with the alcohol reports referring to the in-pregnancy period, with the exception of the report made at 18 months after the delivery (question F), which used a similar type of question.

Other factors, however, should also be considered when trying to explain the differences in reporting for similar time periods. An interviewer effect, leading to lower alcohol reporting could be responsible for differences in questions $\mathrm{A}$ and $\mathrm{B}$ or questions $\mathrm{E}$ and $\mathrm{F}$; in both pairs the lower reports were obtained by interview (questions $\mathrm{A}$ and $\mathrm{F}$ ). However, no interviewer effect was observed in an earlier study using a similar population. ${ }^{9}$ Accuracy of recall diminishes with time and again this could explain some of the variability between questions $\mathrm{E}$ and $\mathrm{F}$. However, other studies using interview data only found higher (rather than lower) alcohol reports at retest. ${ }^{10} 11$ In addition, cultural differences between Denmark and the USA may explain why this study did not confirm the previous findings of a higher intake of alcohol with retrospective reports compared with current reports. ${ }^{12}$ Greater social acceptability of alcohol drinking during pregnancy in Denmark would probably produce similar results for questions $\mathrm{E}$ and $F$, but would not easily explain why a lower intake would be reported with the retrospective question.

When using correlation between measurements as a measure of their reliability, the findings in this study (table IV) are similar to those in others: a Kendall's $\tau$ of 0.67 for the daily absolute alcohol (AA) scores for maternal drinking early in pregnancy over a four month interval between test and retest $;{ }^{10}$ Pearson correlation coefficients of 0.61 for recall of first trimester average daily volume over a three month interval; ${ }^{11}$ and 0.76 for mean daily ounces of alcohol ingested during pregnancy over a two week test-retest interval. ${ }^{13}$ Larger
Pearson correlation coefficients were found $(0.89$ for recall of daily AA scores in the pre-pregnancy period and 0.90 during pregnancy), but the testretest interval was only one week. ${ }^{14}$ Studies based upon alcoholics have in general shown poorer agreement between different measurement methods ${ }^{1516}$ but are not directly comparable with data from this group of normal pregnant women with a generally low to moderate alcohol consumption.

In contrast with our study, similar mean levels of absolute alcohol scores have been reported by some of the other studies on reliability of self reported maternal alcohol consumption. ${ }^{14} 17$ However, also contrasting with this study, the other studies used similar questions in both test and retest occasions. Therefore, it seems that different ways of questioning (eg different phrasing of questions) affect rather the absolute than the relative levels of drinking reported.

SELF REPORTED MATERNAL ALCOHOL

CONSUMPTION AND BIRTH WEIGHT

To what extent can we quantify the effect of maternal alcohol consumption on birth weight? The figure shows that birth weight is negatively associated with all of the alcohol measures, yet if only one of the measures was known to a researcher, he or she might draw different conclusions compared with someone using the same subjects but a different measure of alcohol. As an example, if in this study the alcohol report referring to the period between the 4 th and the 12 th week of gestation was the only one available, one would conclude that no significant association was found between maternal alcohol consumption early in pregnancy and birth weight. Alternatively, if the only available alcohol measure were the report covering the first 36 weeks of gestation then the study would have suggested a significant $250 \mathrm{~g}$ reduction in the mean birth weight in children of women reporting an average alcohol intake during pregnancy of 14 drinks per week.

Without a "gold standard" to measure maternal alcohol consumption the differences of associations with birth weight based upon different types of alcohol reporting cannot be easily interpreted. As an example, when comparing the retrospective overall pregnancy report with the one covering the first 36 weeks, it seems likely that the difference between the slopes of the two lines describing its association with birth weight is due to variability in reporting. However, it could be difficult to say which reporting is the best. On the other hand, even if a "gold standard" to measure alcohol intake were available one would still need to guess about the nature of the impact of maternal alcohol consumption upon the fetus. If susceptibility to alcohol exposure was known to be limited to specific short periods, the questioning should be related to these periods; alternatively, if a cumulative exposure were the relevant factor, then an estimate based on the intake from specific 
short periods (eg questions C or D) could easily lead to more sampling variation of the measurement. In addition, the significant relationship of pre-pregnancy alcohol intake and birth weight (as suggested by the report obtained at the 28 th week of gestation) could be causal or could be explained by the high correlation among reports of maternal drinking before and during pregnancy. Only a careful study design could attempt to distinguish between these two situations. Unfortunately, this and many other characteristics of the relationship between maternal alcohol and birth weight remain largely unknown. ${ }^{5}$

In summary, differences in the way self reported alcohol have been assessed may well explain many of the discrepancies in the results of earlier studies on the effect of maternal alcohol intake and birth weight.

We thank Professor Charles du V Florey for helpful discussions and Anni Overdal for the interviewing. This study has been supported by a grant by the Helsefondet, The Danish National Board of Health and the ECC (EUROMAC). ACP was supported by the Instituto Nacional de Investigação Cientifica and the Hospital de S. Foão-Faculdade de Medicina, Universidade do Porto.

1 Abel EL. Fetal alcohol syndrome. Florida: CRC Press, 1981; vol 1-3.

2 Little R. Moderate alcohol use during pregnancy and decreased infant birth weight. Am $\mathcal{F}$ Public Health 1977; 67 : 1154-6.
3 Wright JT, Waterson EJ, Barrison IC, Toplis PJ, Lewis IG, Gordon MG. Alcohol consumption pregnancy and low birthweight. Lancet 1983; i: $663-5$.

4 Plant ML. Women and alcohol. $A$ review of international literature on the use of alcohol by females. World Health Organization, 1990

5 Olsen J, Pereira A, Olsen SF. Does maternal tobacco smoking modify the effect of alcohol on fetal growth? $A m \mathcal{F}$ Public Health 1991; 81: 69-73.

6 Bracken MB. Perinatal Epidemiology. New York: Oxford University Press, 1984

7 Florey CdV, Taylor D, Bolumar F, Kaminski K, Olsen J, editors EUROMAC, a European concerted action: maternal alcohol consumption and its relation to the outcome of pregnancy and child development at 18 months. Int $\mathcal{F}$ Epidemiol 1992; 21: Suppl 1:

8 Hastie Tiemiol Tibshirani R Generalized additive models: some

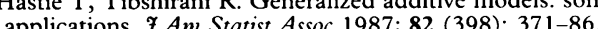

9 Olsen J, Frische G. Comparison between data obtained through questionnaires and interviews: life-style habits of pregnant women. Scand 7 Soc Med 1988; 16: 49-52.

10 Little RE, Mandell W, Schultz FA. Consequences of retrospective measurement of alcohol consumption. I Stud retrospective measurement of alco

11 Robels N, Day NL. Recall of alcohol consumption during pregnancy. F Stud Alcohol 1990; 51(5): 403-7.

12 Ernhart CB, Morrow-Tlucak M, Sokol RJ, Martier S. Underreporting of alcohol use in pregnancy. Alcohol Clin Exp Res 1988; 12(4): 506-11.

13 Little RE, Worthington-Roberts B, Mann SL, Uhl CN. Test-retest reliability of diet and drinking estimates for pregnancy and post partum. Am $\mathcal{F}$ Epidemiol $1984 ; 120(5)$ : 794-7.

14 Streissguth AP, Martin DC, Buffington VE. Test-retest reliability of three scales derived from a quantity-frequencyvariability assessment of self-reported alcohol consumption. Ann NY Acad Sci 1976; 273: 458-66.

15 Davis LJJ, R.M. M. Patient-spouse agreement of the drinking behaviours of alcoholics. Mayo Clin Proc 1987; 62(8): 689-94

16 Fuller RK, Lee $\mathrm{KK}$, Gordis E. Validity of self-report in alcoholism research: results of a veteran administration alcoholistive Alcohol Clin Exp Res 1988; 12(2): 201-5.

17 Fox NL, Sexton M, J.R. H, B. T. The reliability of solf-reports of smoking and alcohol consumption by pregnant women. Addit Behav 1989; 14(2): 187-95. 